\title{
The Combined Use of Silicone and Green Braided Polyester Suture (Ethibond) versus Silicone or Ethibond Alone for Frontalis Suspension Surgery in Children
}

\author{
Hala K Mattout (D), Sameh M Fouda, Sahar Hemeda \\ Ophthalmology Department, Faculty of Medicine, Zagazig University, Zagazig, Egypt \\ Correspondence: Hala K Mattout, Email halamattout@gmail.com; HKMtoot@medicine.zu.edu.eg
}

\begin{abstract}
Purpose: This study aimed to report the outcomes of correcting severe congenital blepharoptosis by frontalis suspension using combined silicone tube and 2-0 green braided polyester suture (Ethibond), and to compare the results with those of silicone rod alone and Ethibond suture alone.

Patients and Methods: The medical records of patients below 16 years who underwent frontalis suspension were retrospectively reviewed. Three groups of patients were identified; group I (16 patients: 22 eyelids) had frontalis suspension surgery using silicone suspension set, group II (18 patients: 25 eyelids) underwent the surgery using Ethibond suture, and group III (15 patients: 23 eyelids) was operated on using combined silicone and Ethibond suture. The primary outcome measures were postoperative marginal reflex distance-1 (MRD-1) and postoperative symmetry, and the secondary outcome measures were the occurrence of complications; mainly recurrence and wound-related complications. The follow-up data were collected after 1 week, 1 month, 6 months, 12 months and every 6 months thereafter.
\end{abstract}

Results: The follow-up period ranged from 18 to 36 months. By the last follow-up visit, 13 eyelids in silicone group (59\%), 11 eyelids in the Ethibond group (44\%), and 13 eyelids in the double sling group (57\%) achieved good surgical correction with MRD1 $\geq 3 \mathrm{~mm}$; these differences were not statistically significant. The difference in symmetry among the three groups was not significant. The highest rates of recurrence $(44 \%)$ and wound-related problems $(8 \%)$ were encountered in the Ethibond group, while the silicone group had no cases of wound-related problems. The lowest recurrence rate $(26.1 \%)$ was in the double sling group but those differences were not significant.

Conclusion: Combined use of silicone and Ethibond suture in frontalis suspension surgery could offer lower recurrence rate and good final surgical outcome when compared to silicone rod or Ethibond suture alone.

Keywords: Ethibond, silicone tube, double sling, frontalis suspension, ptosis

\section{Introduction}

Frontalis suspension is a technique used for the correction of severe ptosis with poor or absent levator muscle function. ${ }^{1-3}$ Poor levator function is identified by the upper lid excursion test when levator induced upper eyelid movement is $4 \mathrm{~mm}$ or less. ${ }^{4,5}$ This suspension technique involves the use of a sling to attach the tarsal plate to the frontalis muscle so that the eyelid elevation movement is achieved by the contraction of frontalis rather that the dysfunctional levator muscle. ${ }^{6,7}$

Frontalis suspension is commonly used for simple congenital ptosis but it can be used to treat ptosis associated with other conditions such as blepharophimosis syndrome, third nerve palsy, double elevator palsy, Marcus Gunn jaw-wink phenomenon and congenital fibrosis syndrome. Benefits of ptosis correction go beyond the cosmetic and psychological effects to a more crucial functional benefit especially in patients with blocked visual axis or with abnormal head posture. $^{8}$ 
Autologous fascia lata is considered by many surgeons the gold-standard sling material due to its durability and autologous nature. However, an increasing preference for non-autologous materials has emerged as they do not involve a second-site scar, decrease the need for general anesthesia, and reduce surgical time and effort. Also, non-autologous materials are particularly useful in patients younger than 3 years in whom fascia lata cannot be harvested. In their continuous search for the ideal sling material, surgeons have investigated and used different alloplastic materials for frontalis suspension including monofilament nylon, braided polyester (Ethibond), silicone, polypropylene (prolene), mersilene mesh, and polytetrafluoroethylene (Gore-tex). ${ }^{8,9}$

Silicone was first used as a sling material by Tillet in $1966 .{ }^{10}$ Since then, silicone has been used as an acceptable sling material by many surgeons. Advantages of silicone include its elasticity that provides a dynamic range of movement for the eyelid; and its decreased integration with the surrounding tissues making it easy to adjust by manipulating the knot or sleeve through the uppermost supra-brow incision and can easily be removed in case of complications. Moreover, it has a lower rate of infection due to its inherent smooth surface that stimulates the least tissue reaction in comparison to other suture materials. However, it was reported to have a higher recurrence rate with a decreased eyelid elevating effect over long periods of follow-up. ${ }^{11}$

Green Braided Coated Polyester (Ethibond) suture is a soft multifilament suture with high tensile strength; its knots are less bulky and more stable than the knots of other suture materials; thus reducing the risk of knots' release and ptosis recurrence. However, its multifilament and non-absorbable nature could lead to inflammation, infection, or granuloma formation. $^{12,13}$

In our search for the ideal sling material, we combined both the elastic silicone and the relatively stable Ethibond to find out the chance of obtaining a synergistic stable effect without increasing the rate of complications; especially recurrence and wound-related problems.

The aim of this study was to report the surgical outcomes of correcting severe congenital blepharoptosis by frontalis sling surgery using combined silicone tube and $2-0$ green braided polyester suture (Ethibond), and to compare the results with those of silicone sling alone and Ethibond suture alone.

\section{Patients and Methods}

The medical records of patients diagnosed with severe blepharoptosis with poor levator function between January 2018 and January 2020 were reviewed retrospectively. Patients included in this study were all patients below 16 years of age who had unilateral or bilateral severe congenital ptosis with poor levator function (upper lid excursion $\leq 4 \mathrm{~mm}$ ) and good Bell's phenomenon. Patients with history of previous operations, patients with myasthenia or progressive ophthalmoplegia, patients with other associated lid anomalies such as blepharophimosis or Marcus -Gunn jaw winking syndrome, patients with preoperative poor Bell's phenomenon or poor corneal sensation and patients who did not attend their follow-up visits up to 18 months following the surgical procedure were not included in this analysis.

This retrospective study was approved by the institutional review board of the Faculty of Medicine, Zagazig University and adhered to the tenets of the Declaration of Helsinki of 1964, as revised in 2013. All patients were operated on at Zagazig University Hospital and a written informed consent was provided by all patients or their guardians before the procedure.

Preoperative data collected from patients' records included: age, gender, side of ptosis, levator excursion, marginal reflex distance-1 (MRD-1), degree of ptosis and duration of follow up. The levator excursion was measured as the patient was moving his eye from a downward gaze to an upward gaze, while negating the frontalis muscle action by thumb pressure over the eyebrow.

The surgeries were performed by any of the three authors; the choice of the sling material was greatly dependent on the surgeon's and patient's preference as well as the availability of the material at the time of operation.

Based on the material used for frontalis sling procedure, three groups of patients were identified; the first group (Group I) included patients who had frontalis sling with silicone rod suspension set (Aurosling ${ }^{\circledR}$, Aurolab, Tamil Nadu, India), the second group (Group II) included patients in which 2-0 green braided polyester (Ethibond) was used as frontalis sling material, and the third group (Group III) included patients who had both silicone and 2-0 Ethibond used as sling material (double sling technique). 
In all patients, frontalis sling procedure was performed under general anesthesia using Fox Pentagon technique. After inserting the corneoscleral protector, the incisions were performed as follows; two stab incisions $3 \mathrm{~mm}$ above upper lid margin in line with the nasal and temporal limbus, two stab incisions just above eye brow hairs in line with the medial and lateral canthi, and a central incision $1 \mathrm{~cm}$ above the brow in line with the pupil. The incisions were then dissected to the level of the frontalis using blunt scissors. The prepared sling material was then passed to the incision sites using either a Wright needle for Ethibond and the double sling cases or the pre-attached needles in cases of silicone rod suspension set; starting from the lowermost incisions above the lid margin and directing upwards passing under the orbicularis oculi muscle and over the tarsus then the orbital septum respectively. In cases of double sling, the silicone tube was detached from the needle of the suspension set then both the Ethibond suture and silicone tube were threaded into the Wright needle and passed simultaneously in the formerly mentioned directions.

The height of the eyelid was adjusted just at the level of the superior limbus in cases where a single sling was used (silicone rod or Ethibond alone) while in cases of double sling the Ethibond suture was tied first with the eyelid level $1 \mathrm{~mm}$ below the upper limbus, then the silicone sling was secured with the sleeve while adjusting the eyelid level at the level of the superior limbus to prevent the relatively stiff Ethibond suture from hindering the movement of the elastic silicone and thus maintaining the silicone's relative advantage of elasticity.

A 6/0 Vicryl suture was used to support the knot and/or the sleeve to the underlying frontalis muscle. The forehead incision was closed meticulously in two layers with 6/0 Vicryl sutures while the rest of the incisions were left un-sutured as they heal rapidly. Frost suture was then placed in the lower eyelid and removed after 48 hours if no severe exposure keratopathy was noted. Cold compresses for the first 48 hours and copious lubricating eye drops were started following removal of the eye patch. Topical antibiotic ointment was prescribed daily at bedtime on long-term basis until spontaneous lid closure during sleep was ensured.

Follow up data were collected after 1 week, 1 month, 6 months, 12 months and every 6 months thereafter.

The evaluated primary outcome measures were:

1) Postoperative marginal reflex distance-1 (MRD-1): based on postoperative MRD1 measured at each follow up visit, surgical correction was categorized as good $(\geq 3 \mathrm{~mm}$ ), fair (MRD 2-2.9 mm), or poor (MRD $<2 \mathrm{~mm}$ ). Unilateral and bilateral cases were evaluated separately.

2) Postoperative symmetry: it was assessed only in bilateral cases to test for the reproducibility of the corrective effect of the sling material in the same patient. Asymmetry was noted when the difference in MRD1 between both eyes was $\geq 1 \mathrm{~mm}$.

Secondary outcome measures were mainly centered around postoperative complications with special emphasis on:

1) Recurrence. It was defined as the conversion of the surgical correction result from good or fair to poor category with the MRD $<2 \mathrm{~mm}$.

2) Wound-related problems such as infection, exposure of the sling material or granuloma formation.

Timing of any recorded complication was also noted and included in our data analysis.

Other complications were also taken into account including; Corneal complications namely exposure keratopathy and lid contour abnormalities such as entropion, ectropion, lash ptosis and irregular eyelid contour.

\section{Statistical Analysis}

The collected data were analyzed using Statistical Package of Social Services, version 25 (SPSS) (IBM, 2017). The distribution characteristics of variables were determined by Shapiro-Wilk test; normally distributed data were analyzed using mean, standard deviation (SD,) range, paired $t$-test and one-way analysis of variance (ANOVA). While nonnormally distributed data were analyzed using median and interquartile range (IQR), and Wilcoxon test. Frequency, percentage, and Pearson's Chi-squared test were used to analyze qualitative data. In all the tests, the $\mathrm{P}$ value of $<0.05$ was taken as significant.

\section{Results}

Record review identified 49 patients meeting the inclusion criteria: 16 patients ( 22 eyelids) had frontalis suspension surgery using silicone suspension set [group I], 18 patients (25 eyelids) underwent frontalis suspension surgery using 
Ethibond suture [group II], and 15 patients (23 eyelids) were operated on using combined silicone and Ethibond suture for frontalis suspension [Group III].

Table 1 shows the demographic data, the preoperative characteristics, and the mean follow up period of the three groups with no detectable statistically significant difference among them.

Table 2 shows the preoperative MRD1 and the postoperative (PO) MRD1 in the first month (initial PO MRD1) and in the last follow up visit (final PO MRD1). To test efficacy of the sling material, the preoperative MRD1 values were compared to those of the initial PO MRD1 within each group. The durability of the sling's corrective effect was assessed

Table I The Preoperative Characteristics of the Three Studied Groups

\begin{tabular}{|c|c|c|c|c|c|}
\hline \multirow[t]{2}{*}{ Variables } & Total & Silicone & Ethibond & Double Sling & $\mathbf{P}$ \\
\hline & $\mathrm{N}=49$ Patients & $n=16$ Patients & $\mathrm{n}=\mid \mathbf{8}$ Patients & $n=15$ Patients & \\
\hline $\begin{array}{l}\text { Age (years): } \\
\text { - Mean } \pm \text { SD } \\
\text { - } \quad \text { Median (IQ range) }\end{array}$ & $\begin{array}{c}5.36+3.3 \\
(1-15)\end{array}$ & $\begin{array}{l}5.7 \pm 3.8 \\
6(1-15)\end{array}$ & $\begin{array}{c}5.3 \pm 3.6 \\
4.5(1-15)\end{array}$ & $\begin{array}{c}5.6 \pm 3.2 \\
5.8(I-12)\end{array}$ & 0.79 \\
\hline $\begin{array}{l}\text { Sex: } \\
\text { - Male } \\
\text { - } \text { Female }\end{array}$ & $\begin{array}{l}29(59.2) \\
20(40.8)\end{array}$ & $\begin{array}{c}10(62.5 \%) \\
6(37.5 \%)\end{array}$ & $\begin{array}{l}11(61 \%) \\
7(39 \%)\end{array}$ & $\begin{array}{l}8(53 \%) \\
7(47 \%)\end{array}$ & 0.8 \\
\hline $\begin{array}{l}\text { Degree of ptosis }(\mathrm{mm}) \\
\text { Mean } \pm \text { SD } \\
\text { Range }\end{array}$ & $\begin{array}{c}3.5 \pm 0.6 \\
(3-5)\end{array}$ & $\begin{array}{c}3.45 \pm 0.5 \\
(3-4)\end{array}$ & $\begin{array}{c}3.56 \pm 0.7 \\
(3-5)\end{array}$ & $\begin{array}{c}3.34 \pm 0.8 \\
(3-5)\end{array}$ & 0.72 \\
\hline $\begin{array}{l}\text { Laterality: } \\
\text { - Unilateral } \\
\text { - } \quad \text { Bilateral }\end{array}$ & $\begin{array}{l}28(57.1) \\
21(42.9)\end{array}$ & $\begin{array}{c}10(62.5 \%) \\
6(37.5 \%)\end{array}$ & $\begin{array}{l}\text { II(6I\%) } \\
7(39 \%)\end{array}$ & $\begin{array}{l}7(47 \%) \\
8(53 \%)\end{array}$ & 0.8 \\
\hline $\begin{array}{l}\text { Follow up (months) } \\
\text { Mean } \pm \text { SD } \\
\text { Range }\end{array}$ & $\begin{array}{c}24.02 \pm 6.1 \\
(18-36)\end{array}$ & $\begin{array}{c}24.25 \pm 5.6 \\
(18-36)\end{array}$ & $\begin{array}{c}23.3 \pm 7.6 \\
(18-36)\end{array}$ & $\begin{array}{c}22.6 \pm 7.0 \\
(18-36)\end{array}$ & 0.95 \\
\hline
\end{tabular}

Table 2 The Changes in MRDI Measurements in the Three Studied Groups

\begin{tabular}{|c|c|c|c|c|c|}
\hline \multirow[t]{4}{*}{ MRDI (mm) } & Total & Silicone & Ethibond & Double Sling & \multirow[t]{4}{*}{$\mathbf{P}$} \\
\hline & ( $N=70$ Eyelids) & ( $n=22$ Eyelids) & ( $n=25$ Eyelids) & ( $n=23$ Eyelids) & \\
\hline & Mean \pm SD & Mean \pm SD & Mean \pm SD & Mean \pm SD & \\
\hline & Range & Range & Range & Range & \\
\hline \multicolumn{6}{|l|}{ Pre-operative } \\
\hline Mean \pm SD & $0.5 \pm 0.6$ & $0.5 \pm 0.5$ & $0.4 \pm 0.7$ & $0.54 \pm 0.6$ & 0.71 \\
\hline Median (range) & I $(-1 / I)$ & $I(0-I)$ & $0.5(-1 / 1)$ & $I(-I / I)$ & \\
\hline Ist month PO (Initial PO) & $3.1 \pm 0.6(2-5)$ & $3.2 \pm 0.6(2-4)$ & $3.2 \pm 0.7(2-5)$ & $3.07 \pm 0.75(2-4)$ & 0.95 \\
\hline 6 month & $2.97 \pm 0.46(2-4)$ & $3.02 \pm 0.6(2-4)$ & $2.94 \pm 0.52(2-4)$ & $2.95 \pm 0.42(2-4)$ & 0.82 \\
\hline 12 month & $2.84 \pm 0.5(1.5-4)$ & $2.95 \pm 0.6(2-4)$ & $2.75 \pm 0.5(1.5-3.5)$ & $2.8 \pm 0.4(2-4)$ & 0.98 \\
\hline Last follow up visit (Final PO) & $2.64 \pm 0.5(I-3)$ & $2.6 \pm 0.52(1.5-3)$ & $2.5 \pm 0.4(I-3)$ & $2.9 \pm 0.65(2-3)$ & 0.38 \\
\hline PI & & $<0.0001 *$ & $<0.0001 *$ & $<0.0001 *$ & \\
\hline P2 & & $<0.000 I^{*}$ & $<0.000 I^{*}$ & $0.002 *$ & \\
\hline
\end{tabular}

Notes: P, difference among the three groups regarding preoperative MRDI and PO MRDI at each visit; PI, difference between preoperative MRDI and initial PO MRDI; P2, difference between initial PO MRDI and final PO MRDI for each group; *statistically significant.

Abbreviations: MRDI, margin reflex distance-I; PO, postoperative. 
by comparing the initial PO MRD1 with the final PO MRD1. No difference was detected among the three groups regarding the MRD1 measured at various occasions, while comparing the preoperative MRD1 with the initial PO MRD1 within each of the studied groups revealed a significant difference. A significant change in MRD1 was also detected on comparing the initial PO MRD1 with the final PO MRD1; denoting significant decrease in the corrective effect of the three studied sling types over time.

Figure 1 shows photos of a patient with severe left ptosis who was operated on using the double sling technique; photos were taken preoperatively (A), in the early postoperative follow up (B), and after 19 months postoperatively (C).

The data presented in Figure 2 show the outcome of surgery for the three studied groups assessed at the last follow up visit. It was noticed that poor outcome was most encountered in Ethibond group (32\%) and least seen in the double sling group ( $8 \%)$; this difference was statistically significant $(\mathrm{p}=0.04)$. More detailed presentation of the differences in the surgical outcome between the studied groups is seen in Table 3.

Lid symmetry in bilateral cases is presented in Table 4 with no significant differences detected among the studied groups.

The main complications are summarized in Table 5. No significant difference was found among the three groups $(\mathrm{p}=0.1)$. However, on testing the difference between silicone group and Ethibond group alone; the difference turned out to be nearly significant $(\mathrm{P}=0.05)$ but this was not the case when the silicone group was compared to the double sling group, with no significant difference detected $(\mathrm{p}=0.08)$. Infections were managed by the use of systemic antibiotics with culture and sensitivity testing in resistant cases. Removal of the sling was performed after 2 postoperative months in one case (Ethibond group) due to persistent infection and subsequent exposure of the sling material. Three of the studied cases developed suture granuloma (2 in Ethibond group, one in the double sling group) and were managed conservatively

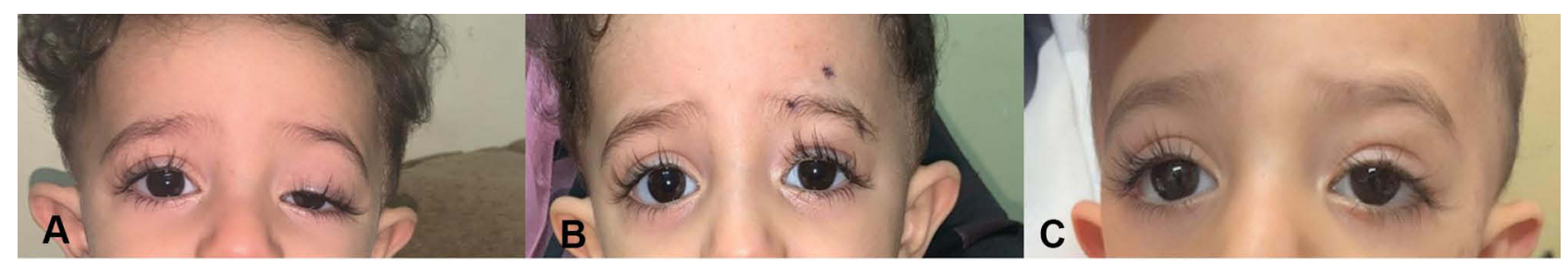

Figure I Photos of a patient with severe left ptosis who was operated on using double sling technique. (A) Preoperative photo. (B) Photo taken in the early follow up period showing good initial postoperative outcome. (C) Photo taken 18 months after the surgery with good final postoperative outcome.

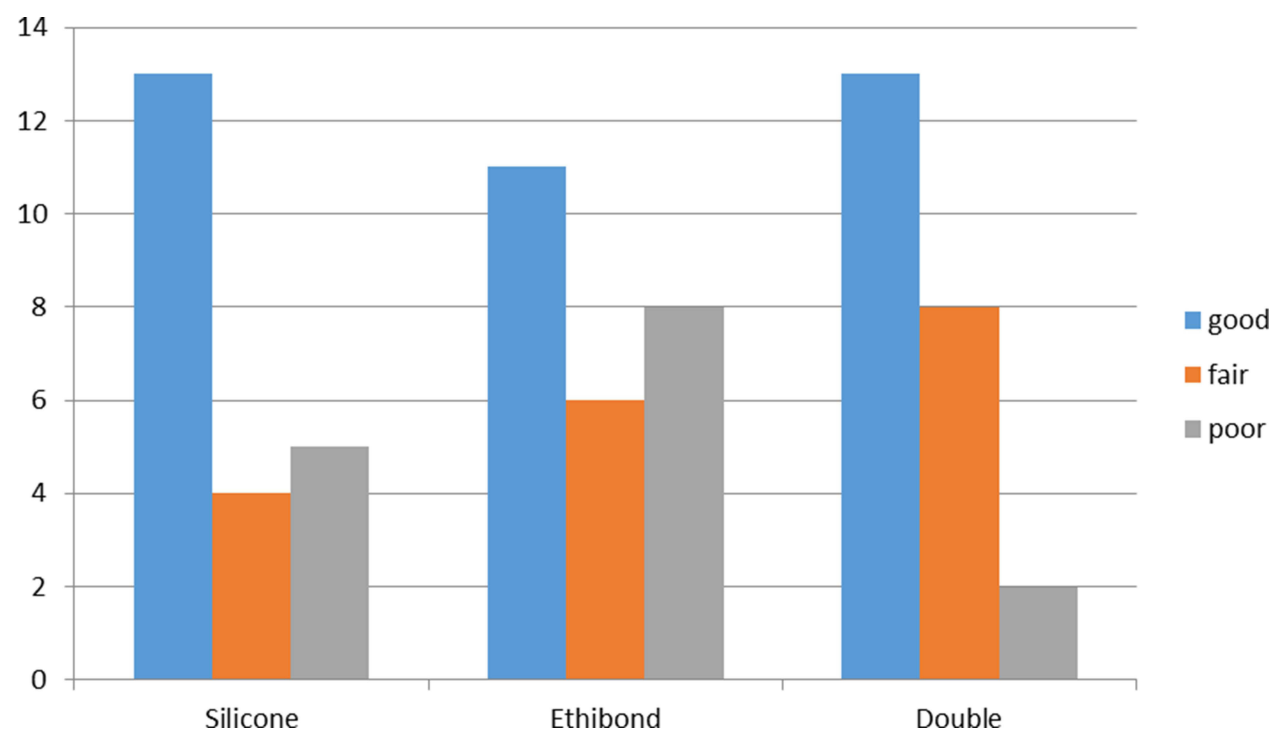

Figure 2 Column chart showing the outcomes of surgery for the three studied groups assessed at the last follow up visit. 
Table 3 Differences in the Surgical Outcomes Between the Studied Groups

\begin{tabular}{|l|l|l|l|l|l|l|l|}
\hline Outcome & $\begin{array}{l}\text { Total } \\
(\mathbf{N}=\mathbf{7 0} \text { Eyelids) } \\
\mathbf{F}(\%)\end{array}$ & $\begin{array}{l}\text { Silicone } \\
(\mathbf{n = 2 2} \text { Eyelids) } \\
\mathbf{F}(\%)\end{array}$ & $\begin{array}{l}\text { Ethibond } \\
(\mathbf{n = 2 5} \text { Eyelids) } \\
\mathbf{F}(\%)\end{array}$ & $\begin{array}{l}\text { Double Sling } \\
(\mathbf{n = 2 3} \text { Eyelids) } \\
\mathbf{F}(\%)\end{array}$ & $\begin{array}{l}\mathbf{P} \\
\text { (Silicone/ } \\
\text { Ethibond) }\end{array}$ & $\begin{array}{l}\mathbf{P} \\
\text { Silicone/Double } \\
\text { Sling }\end{array}$ & $\begin{array}{l}\mathbf{P} \\
\text { Double Sling/ } \\
\text { Ethibond }\end{array}$ \\
\cline { 2 - 8 } & $37(52.9)$ & $13(59 \%)$ & $11(44 \%)$ & $13(57 \%)$ & 0.31 & 0.86 & 0.39 \\
\hline Fair & $18(25.7)$ & $4(18 \%)$ & $6(24 \%)$ & $8(35 \%)$ & 0.52 & 0.21 & 0.52 \\
\hline Poor & $15(21.4)$ & $5(23 \%)$ & $8(32 \%)$ & $2(8 \%)$ & 0.48 & 0.19 & $0.047 *$ \\
\hline
\end{tabular}

Note: *Statistically significant.

Abbreviations: F, frequency; \%, percentage.

Table 4 Postoperative Symmetry in Bilateral Cases

\begin{tabular}{|c|c|c|c|c|c|}
\hline & Total & Silicone & Ethibond & Double Sling & \multirow[t]{3}{*}{$\mathbf{P}$} \\
\hline & $\mathbf{N}=\mathbf{2} \mathbf{I}$ & $(n=6)$ & $(n=7)$ & $(n=8)$ & \\
\hline & $\mathbf{F}(\%)$ & $\mathbf{F}(\%)$ & $\mathbf{F}(\%)$ & F (\%) & \\
\hline Symmetry in bilateral cases & & & & & \\
\hline$\rightarrow$ Symmetrical & $17(80.9)$ & $5(83.4 \%)$ & $5(71.4 \%)$ & $7(87.5 \%)$ & 0.7 \\
\hline$\rightarrow$ Asymmetrical & $4(19.1)$ & $\mathrm{I}(16.6 \%)$ & $2(28.6 \%)$ & $\mathrm{I}(\mathrm{I} 2.5 \%)$ & \\
\hline
\end{tabular}

Notes: $\mathrm{N}$, total number of bilateral cases in each group in which the asymmetry was assessed; $n$, number of bilateral cases in each group. Abbreviations: F, frequency; \%, percentage.

Table 5 The Postoperative Main Complications in the Three Studied Groups

\begin{tabular}{|l|c|c|c|c|}
\hline \multirow{2}{*}{ Complications } & Silicone & Ethibond & Double Sling & P \\
\cline { 2 - 4 } & $\mathbf{( n = 2 2 )}$ & $\mathbf{( n = 2 5 )}$ & $\mathbf{( n = 2 3 )}$ & \\
\hline Granuloma [number (percentage)] & 0 & $2(8 \%)$ & $1(4.3 \%)$ & 0.1 \\
Infection [number (percentage)] & 0 & $2(8 \%)$ & $2(8.7 \%)$ & \\
Total wound-related complications & 0 & $4(16 \%)$ & $3(13 \%)$ & 0.4 \\
\hline Recurrence [number (percentage)] & $8(36.4 \%)$ & $11(44 \%)$ & $6(26.1 \%)$ & 0.5 \\
Mean time of recurrence (months) & $15.4 \pm 3.2$ & $14.8 \pm 6.2$ & $12.3 \pm 4.5$ & \multirow{2}{*}{0} \\
\hline
\end{tabular}

at first but two of them (one in each group) necessitated granuloma excision and wound re-suturing with good outcome. No wound-related complications were detected in the silicone rod group. The mean time of occurrence of these woundrelated problems was $3.25 \pm 1.25$ and $3 \pm 1$ weeks for both the Ethibond and the double sling groups respectively.

Recurrence was highest in the Ethibond group and lowest in the double sling group but the differences were not statistically significant. The recurrence rate and time of recurrence are listed in Table 4.

Lid contour abnormalities were encountered only in one case belonging to the Ethibond group in the form of medial lid margin notching, but it resolved completely after 2 months with lid massage and controlled downward traction of the medial part of the lid margin.

\section{Discussion}

Frontalis sling surgery is the procedure of choice for correcting severe ptosis with poor levator function; it involves connecting the tarsus to the frontalis muscle thus allowing the patient to raise his eyelids by lifting the eyebrow without relying on the poorly-functioning levator muscle. ${ }^{14}$ However, surgeons are continuously seeking the ideal sling material to perform this procedure in short operative time with prolonged effect and with the least possible complications. 
Autogenous fascia lata is theoretically the gold standard material, it was first used by Payr (1909) then by Wright (1922) to treat severe congenital ptosis while its currently practiced technique was introduced by Crawford in $1956 .{ }^{15,16}$ It has optimum durability but it is technically demanding and contraindicated in children younger than 3 years.

As there is no widely accepted sling material, we combined two widely used materials (silicone rod and Ethibond suture) to investigate whether we could obtain the advantages of both materials with the minimum side effects. To the best of our knowledge, this is the first study to combine two sling materials for frontalis suspension and compare the resulting effects with those of using either material alone.

It is believed that any sling material is liable to lose its effect with time especially with the continuous stress exerted by the blinking movements of the eyelid, so, any used material actually acts as a temporary skeleton over which scar tissue could be formed to serve as a permanent bridge between the tarsus and frontalis muscle. As such, the sling material has to hold itself stable in place until adequate scar tissue formation is established. ${ }^{17}$ This stability and subsequent durability of the sling material greatly depends on the biomechanical properties of the material used, such as stress-strain relationship, work of fracture, ultimate tensile strength and elastic properties. In addition, the microstructure and surface roughness of the sling material contribute to its final effect. ${ }^{18-20}$

Choi et $\mathrm{a}^{20}$ used scanning electron microscopy and atomic force microscopy to examine the surface roughness of different sling materials which plays a key role in obtaining adequate sling-cells adhesion. Autogenous fascia lata showed the highest surface roughness followed by the preserved fascia lata, while the silicone rod had the smoothest roughness among the three studied materials. However, silicone appears to have special mechanical properties in the correction of ptosis, as it requires a relatively low force to stretch, with fairly reasonable work of fracture as concluded by Kwon et al. ${ }^{18}$ These elastic properties give the silicone sling a potential advantage of enabling good blinking movement with minimal postoperative lid lag and lagophthalmos which could be more crucial in patients with poor Bell's phenomenon. ${ }^{21}$

On comparing braided polyester (Ethibond) to nine types of 2-0 synthetic suture materials used in frontalis suspension, Greenwald et al reported that Ethibond remained stable in vivo while toughness and strength decreased in all of the other sutures over time. ${ }^{22}$

In the current study, the three types of slings used gave favorable initial surgical outcome, but on comparing the final outcome at the end of the follow up period, we found that Ethibond showed significantly higher rate of poor outcome than the double sling which could be attributed to the additive effect of silicone in the double sling group that maintained the sling stability.

The recurrence rate for silicone and Ethibond varies among different studies ranging from $7 \%$ to $44 \%$ for silicone ${ }^{17,23-27}$ and $17 \%$ to $27 \%$ for Ethibond, ${ }^{8,28,29}$ as shown in Tables 6 and 7. In our study, the recurrence rate was $36 \%$ and $44 \%$ for both silicone and Ethibond respectively. The lowest recurrence rate (26\%) was found in the double sling group denoting that combining the two materials can give a more durable effect that may be attributed to more stimulation of the tissue response and thus reinforcing the fibrosis responsible for the permanent lid elevating effect. The highest recurrence rate in the current study was in the Ethibond group, this could be attributed to the innate nature of

Table 6 The Results of Some Studies Conducted for the Use of Silicone Rod for Frontalis Suspension Surgery

\begin{tabular}{|c|c|c|c|c|}
\hline Study & Number of Eyelids or Patients & Follow Up (Months) & Recurrence & Wound-Related Complications \\
\hline Ben Simon et al ${ }^{17}$ & 27 patients & 20 months & $44 \%$ & $0 \%$ \\
\hline Morris et $\mathrm{al}^{23}$ & II 0 eyelids & 17 months & - & $9 \%$ \\
\hline Lee et $\mathrm{al}^{24}$ & 63 patients & 36 months & $\begin{array}{l}\text { II\% (unilateral) } \\
29 \% \text { (bilateral) }\end{array}$ & - \\
\hline Carter et $\mathrm{al}^{25}$ & 35 patients & 22 months & $7 \%$ & $5 \%$ \\
\hline Buttanri et $\mathrm{al}^{26}$ & 80 eyelids & 16.3 months & $23.75 \%$ & $0 \%$ \\
\hline Rizvi et $\mathrm{al}^{27}$ & 56 eyelids & 12 months & $4 \%$ & $2 \%$ \\
\hline
\end{tabular}


Table 7 The Results of Some Studies Conducted for the Use of Ethibond for Frontalis Suspension Surgery

\begin{tabular}{|c|c|c|c|c|}
\hline Study & Number of Eyelids & Follow Up (Months) & $\begin{array}{l}\text { Recurrence or } \\
\text { Residual Ptosis }\end{array}$ & Wound-Related Complications \\
\hline Molinari et $\mathrm{al}^{28}$ & 43 & 38.6 & - & $6(13.9 \%)$ \\
\hline Bajaj et $\mathrm{al}^{29}$ & 30 & $16 \pm 3.24$ & $17 \%$ & $2(13 \%)$ \\
\hline Wasserman et al ${ }^{8}$ & $\mathrm{II}$ & 8 & $27.3 \%$ & I (9.1\%) \\
\hline
\end{tabular}

Ethibond as a non-absorbable multifilament suture with the possibility of producing more pronounced inflammatory response in vivo as individual filaments can detach from the main suture mass with each one stimulating its own tissue reaction, which can also weaken the suture and increase the incidence of recurrence as well. ${ }^{30,31}$

On studying the lid symmetry in bilateral cases, no significant differences were found among the three groups, denoting the reproducible effect of the three types of slings.

In the current study, no wound-related complications were encountered in the silicone group, which is in agreement with the studies conducted by Ben Simon et $\mathrm{al}^{17}$ and Buttanri et al, ${ }^{26}$ while the Ethibond group showed the highest complication rate (16\%) that is comparable to the results of Molinari et al ${ }^{28}$ and Bajaj et al. ${ }^{29}$ Patients treated with double sling showed a complication rate close to that of Ethibond alone (13\%) suggesting that combining the two types of sling materials was not associated with increased rate of wound-related complications despite increasing the final knots size.

Points that increase the trust in the results of this study are adopting one surgical technique for all materials, excluding recurrent and acquired cases of severe ptosis, excluding ptosis associated with other syndromes, and limiting the analysis to a single age group (below 16 years of age).

Limitations of the current study are its retrospective design, absence of patient satisfaction assessment due to young age of the studied patients making satisfaction assessment relatively unreliable.

\section{Conclusion}

Combined use of silicone and Ethibond suture in frontalis suspension surgery could offer lower recurrence rate and good final surgical outcome when compared to silicone rod or Ethibond suture alone.

\section{Disclosure}

The authors report no conflicts of interest in this work.

\section{References}

1. Katowitz JA. Frontalis suspension in congenital ptosis using a polyfilament, cable-type suture. Arch Ophthalmol. 1979;97:1659-1663. doi:10.1001/ archopht.1979.01020020227009

2. Steinkogler FJ, Kuchar A, Huber E, Arocker-Mettinger E. Gore-Tex soft tissue patch frontalis suspension technique in congenital ptosis and in blepharophimosis-ptosis syndrome. Plast Reconstr Surg. 1993;92:1057-1060. doi:10.1097/00006534-199311000-00009

3. Wagner RS, Mauriello JA, Nelson LB, Calhoun JH, Flanagan JC, Harley RD. Treatment of congenital ptosis with frontalis suspension: a comparison of suspensory materials. Ophthalmology. 1984;91:245-248. doi:10.1016/S0161-6420(84)34298-1

4. Kim CY, Yoon JS, Bae JM, Lee SY. Prediction of postoperative eyelid height after frontalis suspension using autogenous fascia lata for pediatric congenital ptosis. Am J Ophthalmol. 2012;153(2):334-342. doi:10.1016/j.ajo.2011.07.023

5. Beyer CK, Albert DM. The use and fate of fascia lata and sclera in ophthalmic plastic and reconstructive surgery. Ophthalmology. 1981;88:869-886.

6. Crawford JS. Repair of ptosis using frontalis muscle and fascia lata: a 20 year review. Ophthalmic Surg. 1977;8(4):31-36.

7. Downes RN, Collin JR. The mersilene mesh sling—a new concept in ptosis surgery. Br J Ophthalmol. 1989;73:498-501. doi:10.1136/bjo.73.7.498

8. Wasserman BN, Sprunger DT, Helveston EM. Comparison of materials used in frontalis suspension. Arch Ophthalmol. 2001;119(5):687-691. doi:10.1001/archopht.119.5.687

9. Hintschich CR, Zurcher M, Collin JR. Mersilene mesh brow suspension: efficacy and complications. Br J Ophthalmol. 1995;79(4):358-361. doi:10.1136/bjo.79.4.358

10. Tillet CW, Tillet GM. Silicone sling in the correction of ptosis. Am J Ophthalmol. 1966;62:521-523. doi:10.1016/0002-9394(66)91334-1

11. Mokhtarzadeh A, Harrison AR. Controversies and advances in the management of congenital ptosis. Expert Rev Ophthalmol. 2015;10(1):59-63.

12. Yulish M, Pikkel J. Evaluation of polybutylate-coated braided polyester (Ethibond) sutures for levator-advancement blepharoptosis repair. Ophthalmol. 2012;2012:763731. 
13. Everett WG. Sutures, incisions and anastomoses. Ann R Coll Surg Engl. 1970;8:14-16.

14. Bilgin LK, Yeniad B. The long-term results of frontalis suspension using autogenous fascia lata in children with congenital ptosis under 3 years old. Plast Surg Int. 2010;2010:609462.

15. Crawford JS. Repair of ptosis using frontalis muscle and fascia. Trans Am Acad Ophthalmol Otolaryngol. 1956;60(5):672-678.

16. Philandrianos C, Galinier P, Salazard B, Bardot J, Magalon G. Long-term outcome of frontalis suspension using autogenous temporal fascia or fascia lata in children. J Plast Reconstr Aesthet Surg. 2010;63(5):782-786. doi:10.1016/j.bjps.2009.01.083

17. Ben Simon GJ, Macedo AA, Schwarcz RM, Wang DY, McCann JD, Goldberg RA. Frontalis suspension for upper eyelid ptosis: evaluation of different surgical designs and suture material. Am J Ophthalmol. 2005;140(5):877-885. doi:10.1016/j.ajo.2005.05.031

18. Kwon KA, Shipley RJ, Edirisinghe M, et al. Microstructure and mechanical properties of synthetic brow-suspension materials. Mater Sci Eng C Mater Biol Appl. 2014;35:220-230. doi:10.1016/j.msec.2013.10.031

19. Madsen ET. An experimental and clinical evaluation of surgical suture materials. Surg Gynecol Obstet. 1958;106(2):216-224.

20. Choi S, Shin JH, Cheong Y, Lee HJ, Jin KH, Park HK. Nano-structural investigation of frontalis sling biomaterial surfaces. Scanning. 2011;33 (6):419-425.

21. Shah KP, Mukherjee B. Efficacy of frontalis suspension with silicone rods in ptosis patients with poor Bell's phenomenon. Taiwan J Ophthalmol. 2017;7(3):143-148. doi:10.4103/tjo.tjo_36_17

22. Greenwald D, Shumway S, Albear P, Gottlieb L. Mechanical comparison of 10 suture materials before and after in vivo incubation. J Surg Res. 1994;56(4):372-377. doi:10.1006/jsre.1994.1058

23. Morris CL, Buckley EG, Enyedi LB, Stinnett S, Freedman SE. Safety and efficacy of silicone rod frontalis suspension surgery for childhood ptosis repair. J Pediatr Ophthalmol Strabismus. 2008;45(5):280-288. doi:10.3928/01913913-20080901-11

24. Lee MJ, Oh JY, Choung HK, Kim NJ, Sung MS, Khwarg SI. Frontalis sling operation using silicone rod compared with preserved fascia lata for congenital ptosis a three-year follow-up study. Ophthalmology. 2009;116(1):123-129. doi:10.1016/j.ophtha.2008.08.049

25. Carter SR, Meecham WJ, Seiff SR. Silicone frontalis slings for the correction of blepharoptosis: indications and efficacy. Ophthalmology. 1996;103 (4):623-630. doi:10.1016/S0161-6420(96)30643-X

26. Buttanri IB, Serin D, Karslioglu S, Akbaba M, Ari S, Fazil K. Effect of suturing the silicone rod to the tarsal plate and the suture material used on success of frontalis suspension surgery. Ophthalmic Plast Reconstr Surg. 2013;29(2):98-100. doi:10.1097/IOP.0b013e31827a0068

27. Rizvi SA, Gupta Y, Yousuf S. Evaluation of safety and efficacy of silicone rod in tarsofrontalis sling surgery for severe congenital ptosis. Ophthalmic Plast Reconstr Surg. 2014;30(1):11-14. doi:10.1097/IOP.0b013e3182a74f44

28. Molinari A, Weaver DT, Goldblum TA, Silbert D, Lopez SP, Matta N. Pediatric frontalis suspension with braided polyester: a comparison of two techniques. J Pediatr Ophthalmol Strabismus. 2018;55(4):229-233. doi:10.3928/01913913-20180213-02

29. Bajaj MS, Sastry SS, Ghose S, Betharia SM, Pushker N. Evaluation of polytetrafluoroethylene suture for frontalis suspension as compared to polybutylate-coated braided polyester. Clin Exp Ophthalmol. 2004;32(4):415-419. doi:10.1111/j.1442-9071.2004.00818.x

30. Postlethwait RW. Long-term comparative study of nonabsorbable sutures. Ann Surg. 1970;171(6):892-898. doi:10.1097/00000658-19700601000010

31. Setzen G, Williams EF. Tissue response to suture materials implanted subcutaneously in a rabbit model. Plast Reconstr Surg. 1997;100:1788-1795. doi:10.1097/00006534-199712000-00023

Clinical Ophthalmology

Dovepress

\section{Publish your work in this journal}

Clinical Ophthalmology is an international, peer-reviewed journal covering all subspecialties within ophthalmology. Key topics include: Optometry; Visual science; Pharmacology and drug therapy in eye diseases; Basic Sciences; Primary and Secondary eye care; Patient Safety and Quality of Care Improvements. This journal is indexed on PubMed Central and CAS, and is the official journal of The Society of Clinical Ophthalmology (SCO). The manuscript management system is completely online and includes a very quick and fair peer-review system, which is all easy to use. Visit http://www. dovepress.com/testimonials.php to read real quotes from published authors.

Submit your manuscript here: https://www.dovepress.com/clinical-ophthalmology-journal 